\title{
NUTRITIONAL STATUS ASSESSMENT IN PATIENTS WITH CYSTIC FIBROSIS
}

Rubio Almanza M, Ramos Prol A, García Malpartida K, Argente Pla M, León De Zayas B, Navas De Solís S, Campos Alborg V, Sanchís Martín S, Querol Ripoll R, Merino Torres JF

\section{Introduction}

Cystic fibrosis (CF) is a chronic disease at risk of malnutrition. The aim of the study is to assess nutritional status of patients with CF

\section{Results}

\section{Diagnosed malnutrition}

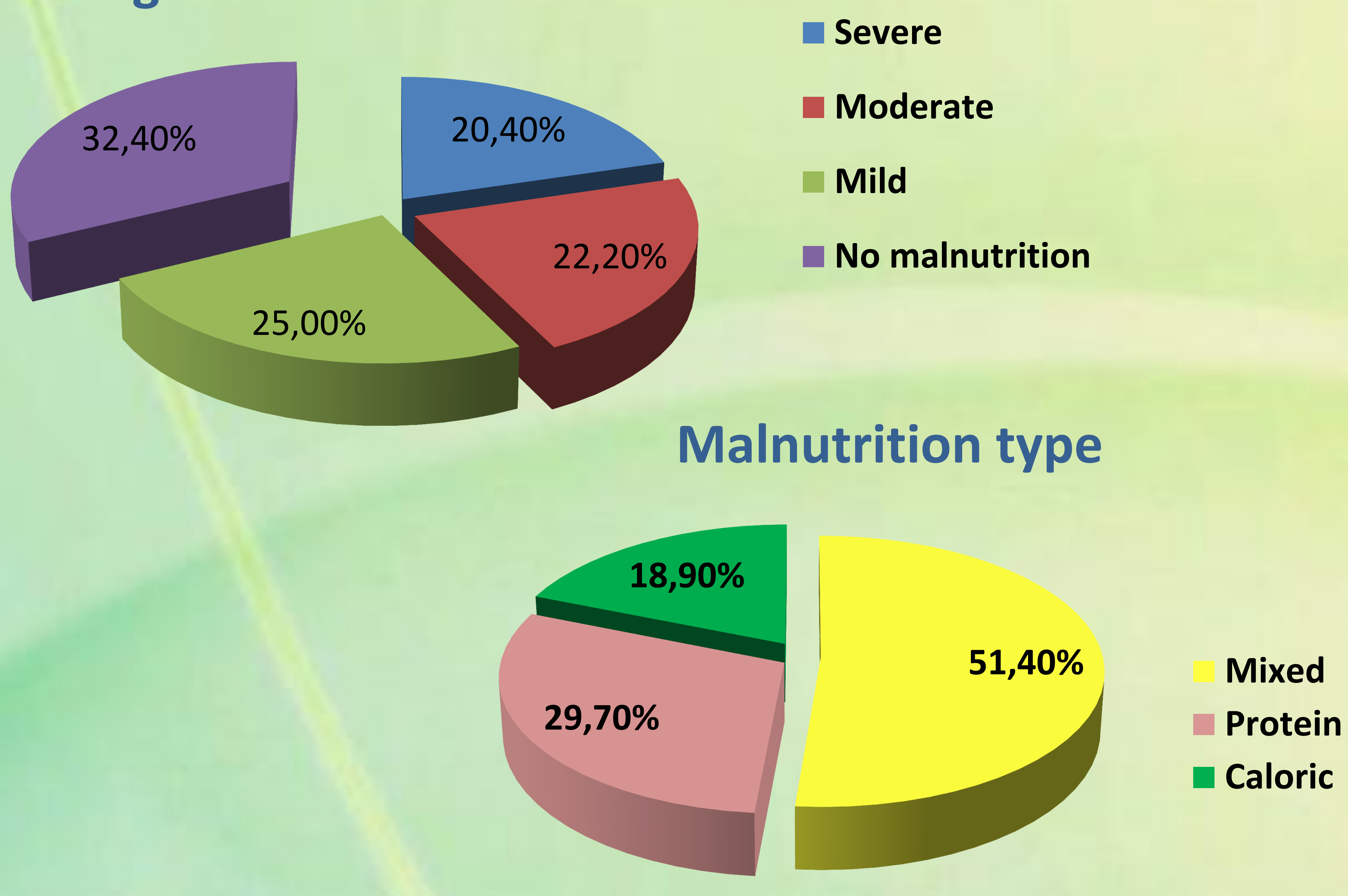

Diabetes was associated with vitamin D deficiency $<30 \mathrm{ng} / \mathrm{ml}$ $(p=0.01)$ and lung transplantation $(p<0.001)$. Severe malnutrition is statistically associated with lung transplantation ( $p=0.01$ ), systemic corticosteroid therapy ( $p$ $=0.01)$ and diabetes $(p=0.04)$.

\section{Methods}

Descriptive study of CF patients referred for a nutritional evaluation. Data collected included lung function, pancreatic and carbohydrate metabolism (according to ADA's diagnostic criteria), anthropometric and laboratory parameters. Results are shown as mean (SD).

Number of patients

64

Mean age (years)

$26,8(7,4)$

Respiratory involvement (\%)

100

Exocrine pancreatic disfunction (\%)

93,4

Lung trasplantation (\%)

29,5

Lung trasplantation 's mean age (years)

22,4

Diabetic (\%)

50

Prediabetic (\%)

21,9

Systemic corticosteroid treatment (\%)

37,5

BMI (Kg/m2)

$19,2(2,7)$

Ideal percentage weight (\%)

$83,9(13,3)$

Weight loss in the last 6 months (\%)

$3,6(5,8)$

Main causes of weight loss (\%)

-Respiratory infections

-Early satiety

32,1

-Steatorrhea

14,8

Vitamins deficiency (\%)

vit $D$

60,9

vit $A$

vit $E$

\section{CONCLUSIONS}

A high prevalence of malnutrition (73\%) was found in CF patients. Severe malnutrition was associated with lung transplantation, systemic corticosteroid therapy and diabetes. Pretransplant assessment of nutritional status is important in CF patients. Diabetes was associated with lung transplantation and vitamin $D$ deficiency. 